\title{
Prospective population-based study on the survival of patients with lung cancer
}

\author{
R. Mäkitaro*, P. Pääkko*, E. Huhti*, R. Bloigu`, V.L. Kinnula*
}

Prospective population-based study on the survival of patients with lung cancer. R. Mäkitaro, P. Pääkko, E. Huhti, R. Bloigu, V.L. Kinnula. C) ERS Journals Ltd 2002. ABSTRACT: The purpose of this study was to evaluate the change, over $20 \mathrm{yrs}$, in the survival of lung cancer patients in a population-based study.

Information on all patients with lung cancer in a defined geographical area during 1990-1992 $(n=602)$ was prospectively gathered. The survival of these patients was assessed and also compared with the results of a similar study in the same area during the years 1968-1971 $(n=446)$.

The 5-yr survival had improved during 20 yrs from $4 \%$ to $12 \%$. The 5-yr survival of the patients with squamous cell carcinoma had increased from $6 \%$ to $16 \%$, and adenocarcinoma from $4 \%$ to $19 \%$, whereas the survival of small cell carcinoma had remained the same ( $2 \%$ and $3 \%$, respectively). Even though the recent patients were older than those of the earlier series the proportion of surgically treated patients had remained the same $(16 \%$ and $20 \%)$, but the 5-yr survival of patients who had been operated on had increased significantly from $23 \%$ to $48 \%$. The differences in survival in the second cohort (1990-1992) between histological types (Chi-squared logrank=59.2), tumour, node, metastasis stages (Chi-squared logrank=199.6), symptomatic stages (Chi-squared logrank=120, $\mathbf{p}<\mathbf{0 . 0 0 1}$ ) and treatment (Chi-squared logrank=277) were significant.

Based on this study the independent prognostic factors for better survival of lung cancer patients are tumour, node, metastasis stages I and II, surgical treatment and Feinstein's symptomatic stages I and II.

Eur Respir J 2002; 19: 1087-1092.
Depts of *Internal Medicine, " Pathology and "Medical Faculty, University of Oulu, and Oulu University Hospital, Oulu, Finland.

Correspondence: R. Mäkitaro, Dept of Internal Medicine, Oulu University Hospital, Kajaanintie 50, FIN-90220 Oulu, Finland.

Fax: 35883154139

E-mail: riitta.makitaro@oulu.fi

Keywords: Lung cancer population-based study survival

Received: May 292000

Accepted after revision December 5 2001

This research was supported by the Finnish Anti-Tuberculosis Association Foundation and the Cancer Society of North Finland.
Lung cancer is common among males and increasingly common among females in industrialized countries throughout the world. The prognosis of this disease is still poor $[1,2]$. However, given that both diagnostic techniques and treatment modalities have improved, the prognosis of lung cancer patients may have improved. Fibreoptic bronchoscopy is used routinely to facilitate the diagnosis, and modern imaging methods enable better sampling procedures and more precise staging of tumours. The treatment of choice for nonsmall cell lung cancer, i.e. radical surgery, has remained the same, but the surgical techniques and postoperative treatments have improved. Clinical studies addressing the effects of chemotherapy and combination therapy, especially in small cell carcinoma and stage III disease have suggested that they prolong survival [3-5]. Many of these studies have, however, been conducted in centres with a particular interest in chemotherapy and in groups of patients with strictly defined inclusion criteria. Thus, these studies are useful in the assessment of new chemotherapeutic agents, but they do not give information about the survival of lung cancer patients in general. Most of the population-based studies available are retrospective register- or hospital-based investigations [6-8]. These studies may only include a selected group of patients and often have low diagnostic accuracy in comparison with prospectively collected patient series.

There are only a few studies where unselected patients of lung cancer have been followed for several years. Therefore the present authors conducted a population-based, prospective study to evaluate the 5 -yr survival of all patients with lung cancer in a defined geographical area. Importantly, a similar survey had been conducted in this area during the years 1968-1971, and therefore the results of the present study could be compared with those obtained 20-yrs-ago.

\section{Methods}

The study was conducted in the province of Oulu in northern Finland with a population of 442,900 at the end of 1991. Every patient who had lung cancer diagnosed between 1990-1992 was followed-up for 5 yrs or until death. During the 3 yrs, 602 patients with lung cancer were diagnosed, 92 females and 510 males. Most of the patients (443 patients, $74 \%$ ) were personally interviewed by two of the authors. The patients mean \pm SD age was $67.7 \pm 9.9$ yrs. Fibreoptic bronchoscopy was performed on 452 patients $(75 \%)$, and $17(3 \%)$ underwent mediastinoscopy. Computed 
tomography (CT) was conducted on 358 patients $(59 \%)$. Tumour, node, metastasis (TNM) classification and staging of the cancer [9] were carried out for $519(86 \%)$ patients. The number of autopsies was 79 $(13 \%)$. A histological and/or cytological diagnosis was obtained in 516 cases $(85 \%)$. The follow-up period started on the day when the diagnosis was first made; histological and/or cytological confirmation, if possible, usually came later.

The lung cancers were classified into five histological groups according to the World Health Organization criteria [10]: 1) squamous cell carcinoma, 2) small cell carcinoma, 3) adenocarcinoma, 4) large cell carcinoma, 5) other or unclassified forms. The last group included mainly cases where the sample was inadequate for classification, but allowed the diagnosis of a malignant tumour. All the pathological slides were re-examined by an experienced lung pathologist. Cases considered as metastasis of a primary cancer outside the lung were excluded. In 86 patients $(14 \%)$ the diagnosis could not be confirmed histologically or cytologically.

The patients were classified into the four symptomatic stages described by FEINSTEIN and Wells [11]: stage I: asymptomatic; stage II: primary symptoms only; stage III: systemic symptoms with or without primary symptoms, but no metastatic symptoms; stage IV: metastatic symptoms, with or without primary symptoms and with or without systemic symptoms. The symptomatic stage was decided at the patients' first interview.

If there were no contraindications (other diseases, nonoperability) and the patient agreed, all the patients with nonsmall cell cancer were operated on. The other treatment modalities included radiotherapy, chemotherapy (the most common agents being vincristine, doxorubicin and cyclophosphamide), a combination of radio- and chemotherapy, or supportive treatment.

Approximately 20-yrs earlier, during 1968-1971, and in largely the same geographical area, a prospective, population-based survey of lung cancer was carried out with many similar methods of patient identification [12]. A total of 446 patients were diagnosed during 4 yrs in a population of approximately 300,000 individuals. The patients' mean \pm SD age was $61.9 \pm 9.1$ yrs. Histological or cytological confirmation of the diagnosis was achieved in 431 cases $(97 \%)$. Squamous cell carcinoma was the most common histological type $(47 \%)$, followed by small cell carcinoma $(27 \%)$, adenocarcinoma $(11 \%)$ and large cell carcinoma $(4 \%)$. Seventy-one patients $(16 \%)$ were operated on. Additional unpublished data were also drawn from the present authors' earlier series for comparison. The survival of the patients in both series was compared.

\section{Statistical analyses}

Survival data were analysed using the survival curves and the Kaplan-Meier method. The Chisquared test was used to assess the difference in patient survival according to different factors (age, sex, histological types, TNM staging, treatment and symptomatic stages). Multivariable analysis of these prognostic variables was performed using Cox regression. A $\mathrm{p}<0.05$ was considered significant.

\section{Results}

The overall survival rates of the patients in the present and earlier series are shown in figure 1 and table 1 . The 5-yr survival was better in the present $(12 \%)$ than in the earlier series $(4 \%)(p<0.001)$. Since the prognosis of small cell carcinoma is particularly poor with very few patients alive after 5 yrs, the 2-yr survival was also assessed; this did not differ from the earlier series $(19 \%$ and $15 \%$, respectively, $\mathrm{p}=0.079)$. The survival rates of males and females were similar. It should also be noted that the subjects in the present series were generally older, the mean age being $68 \mathrm{yrs}$ in the present and $62 \mathrm{yrs}$ in the earlier series.

\section{Histological type of tumour and survival}

The patients with adenocarcinoma had the best 5-yr survival $(19 \%)$ which increased significantly during the $20 \mathrm{yrs}(\mathrm{p}=0.006)$. The 5 -yr survival of the patients with squamous cell carcinoma also increased significantly, from $6 \%$ to $16 \%(\mathrm{p}<001)$ (table 1$)$.

\section{Tumour, node, metastasis staging and survival}

In the earlier series TNM-classification was performed according to the version published by the International Union Against Cancer in 1968. TNMclassification has changed twice since then, in 1978 and 1986. Due to the difference in staging categories, TNM stages between these surveys were not compared. Clinical TNM-classification and staging were available in 519 cases $(86 \%)$ in the present series. The survival patterns for stage I and II were similar. As expected the patients with stage IV (metastatic) disease had the worst prognosis (table 1).

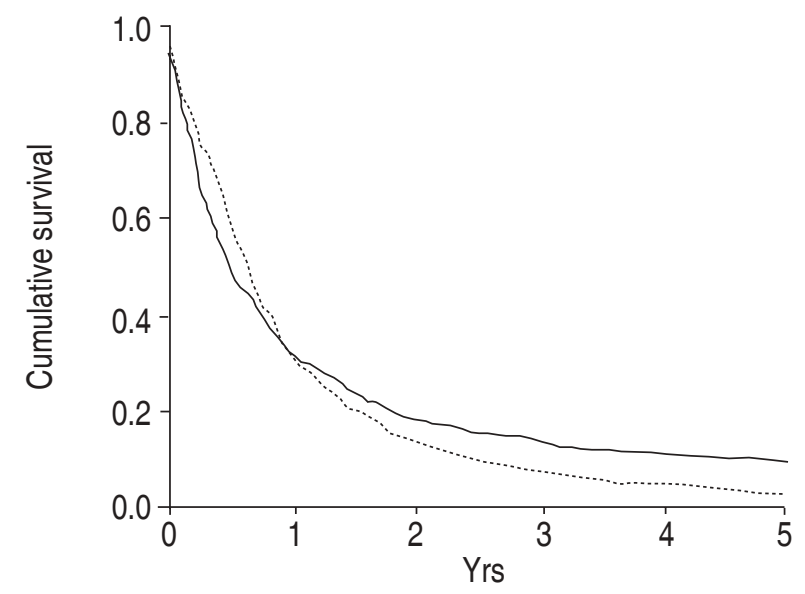

Fig. 1.-Survival of lung cancer patients in the years 1968-1971 $(\cdots \cdots \cdots . . . ; 12])$ and 1990-1992 (-). 
Table 1. - Survival data of lung cancer patients according to different factors in the years 1968-1971 [12] and 1990-1992

\begin{tabular}{|c|c|c|c|c|c|c|c|}
\hline \multirow[t]{2}{*}{ Factor } & \multicolumn{3}{|c|}{ 1968-1971 survey } & \multicolumn{3}{|c|}{ 1990-1992 survey } & \multirow{2}{*}{$\begin{array}{l}\text { Comparison } \\
\text { between surveys }\end{array}$} \\
\hline & $\mathrm{n}(\%)^{+}$ & $2 \mathrm{yrs}^{\#}$ & $5 \mathrm{yrs}^{\top}$ & $\mathrm{n}(\%)^{+}$ & $2 \mathrm{yrs}^{\#}$ & $5 \mathrm{yrs}^{\top}$ & \\
\hline All patients & $446(100)$ & $66(15)$ & $19(4)$ & $602(100)$ & $114(19)$ & $72(12)$ & $\mathrm{n} 2 \mathrm{p}=0.79$ \\
\hline Male & $420(94)$ & $62(15)$ & $19(4)$ & $510(85)$ & $92(18)$ & $59(12)$ & \\
\hline Female & $26(6)$ & $4(15)$ & 0 & $92(15)$ & $22(24)$ & $13(14)$ & \\
\hline \multicolumn{8}{|l|}{ Histological type } \\
\hline Squamous cell carcinoma & $198(44)$ & $40(20)$ & $12(6)$ & 204 (34) & $54(26)$ & $33(16)$ & $\mathrm{p}<0.001$ \\
\hline Adenocarcinoma & $50(11)$ & $9(18)$ & $2(4)$ & $135(22)$ & $31(23)$ & 25 (19) & $p=0.006$ \\
\hline Small cell carcinoma & $115(26)$ & $5(4)$ & $2(2)$ & $121(20)$ & $9(7)$ & $4(3)$ & NS \\
\hline Large cell carcinoma & $21(5)$ & $2(10)$ & $1(5)$ & $23(4)$ & $4(17)$ & $2(9)$ & NS \\
\hline Other unclassified & $47(11)$ & 7 (15) & $2(4)$ & $33(6)$ & $9(27)$ & $6(18)$ & NS \\
\hline No histology & $15(3)$ & $3(20)$ & $0(0)$ & $86(14)$ & $7(8)$ & $2(2)$ & NS \\
\hline Comparison between types & \multicolumn{3}{|c|}{$\chi^{2}$ logrank $=67.9, p<0.001$} & \multicolumn{3}{|c|}{$\chi^{2}$ logrank $=59.2, p<0.001$} & \\
\hline TNM staging & & & & $519(86)$ & & & \\
\hline Stage I & & & & 97 (19) & $56(58)$ & $41(42)$ & \\
\hline Stage II & & & & $21(4)$ & $13(62)$ & $7(33)$ & \\
\hline Stage IIIA & & & & $57(11)$ & $19(33)$ & $10(18)$ & \\
\hline Stage IIIB & & & & $128(25)$ & $16(13)$ & $10(8)$ & \\
\hline Stage IV & & & & $216(41)$ & $6(3)$ & $2(1)$ & \\
\hline Comparison between stages & \multirow{2}{*}{\multicolumn{7}{|c|}{$\chi^{2}$ logrank $=199.6, p<0.001$}} \\
\hline Treatment & & & & & & & \\
\hline Surgery & $71(16)$ & $33(46)$ & $17(24)$ & $123(20)$ & $79(64)$ & $59(48)$ & $\mathrm{p}<0.001$ \\
\hline Chemotherapy & $58(13)$ & $3(5)$ & $0(0)$ & $20(3)$ & $2(10)$ & $1(5)$ & NS \\
\hline Radiotherapy & $150(33)$ & 19 (13) & $2(1)$ & 189 (32) & $22(11)$ & $8(4)$ & NS \\
\hline Combination & $79(18)$ & $9(11)$ & $0(0)$ & $54(9)$ & $6(11)$ & $2(4)$ & NS \\
\hline No treatment & $68(20)$ & $2(2)$ & $0(0)$ & $216(36)$ & $5(2)$ & $0(0)$ & NS \\
\hline Comparison between treatment & \multicolumn{3}{|c|}{$\chi^{2}$ logrank $=218.7, p<00.1$} & \multicolumn{3}{|c|}{$\chi^{2} \operatorname{logrank}=227, \mathrm{p}<00.1$} & \\
\hline Symptomatic stages & $441(99)$ & & & $517(86)$ & & & \\
\hline No symptoms & $70(16)$ & $21(30)$ & $7(10)$ & $47(9)$ & $25(53)$ & $18(38)$ & $\mathrm{p}<0.001$ \\
\hline Primary symptoms & $140(32)$ & $30(21)$ & $11(8)$ & $141(27)$ & $43(30)$ & $30(21)$ & $\mathrm{p}<0.001$ \\
\hline Systemic symptoms & $127(29)$ & $13(10)$ & $1(1)$ & $217(42)$ & $39(18)$ & $18(8)$ & $\mathrm{p}<0.001$ \\
\hline Metastatic symptoms & $104(23)$ & $2(2)$ & $0(0)$ & $112(22)$ & $1(1)$ & $0(0)$ & NS \\
\hline Comparison between stages & \multicolumn{3}{|c|}{$\mathrm{k}=99, \mathrm{p}<0.001$} & \multicolumn{3}{|c|}{$\chi^{2}$ logrank $=120, p<0.001$} & \\
\hline
\end{tabular}

${ }^{+}$: Number of patients at the beginning ( $\%$ of all patients in survey with data on factor considered); ${ }^{*}:$ number and percentage surviving for $2 \mathrm{yrs;}{ }^{\top}$ : number and percentage surviving for 5 yrs. TNM: tumour, node, metastasis; NS: nonsignificant; $\chi^{2}$ : chisquared; n2: 2-yr survival rate comparison; n5: 5-yr survival rate comparison.

\section{Symptomatic stages and survival}

The symptomatic stages described by FEINSTEIN and WELLS [11] could be defined for $441(99 \%)$ in the earlier series and for $517(86 \%)$ in the present series of patients. In agreement with the previous study, survival was best among asymptomatic patients and worst among those with metastatic symptoms; none of the latter survived for 3 yrs (table 1).

\section{Treatment and survival}

The survival of patients treated surgically was the best. A combination of radiation and chemotherapy was given to 54 patients (48 small cell and six nonsmall cell carcinoma); only two of them survived for 5 yrs. The 2-yr survival of the patients with small cell carcinoma, who received combination therapy, was $12.5 \%$ (six out of 48 patients). None of the small cell carcinoma patients treated with chemotherapy, radiation or supportive care alone survived for 2 yrs. Excluding operated patients the survival rates between other treatment modalities differed significantly (Chi-squared logrank $=66.4, p<0.001)$. However, these treatment groups were not comparable. The patients with no active treatment had the shortest survival (table 1).

Factors analysed jointly for prognostic significance included TNM stage, symptomatic stage, histology, age, sex and treatment (table 2). TNM-stage I or II was the most significant predictor of survival. Independent prognostic factors for survival were surgical treatment and Feinstein and Wells [11] symptomatic stages I or II. Conversely, histology,

Table 2.-Factors analysed jointly for prognostic significance

$$
\begin{array}{ccc}
\operatorname{Exp}(\beta) \quad \operatorname{SE}(\beta) & \text { p-value } 95 \% \mathrm{CI} \\
& \text { for } \operatorname{Exp}(\beta)
\end{array}
$$

\begin{tabular}{lllll}
\hline Age & 1.0084 & 0.0052 & 0.1070 & $0.9982-1.0187$ \\
Histology & 1.0089 & 0.0327 & 0.7861 & $1.0089-1.0757$ \\
TNM stage & 1.435 & 0.0441 & 0.000 & $1.4169-1.6845$ \\
Treatment & 1.3433 & 0.0378 & 0.000 & $1.309-1.5180$ \\
Sex & 1.1372 & 0.1378 & 0.3195 & $0.6655-1.1421$ \\
\hline
\end{tabular}

Exp ( $\beta)$ : hazard ratio; SE $(\beta)$ : standard error of beta; $95 \%$ CI for $\operatorname{Exp}(\beta): 95 \%$ confidence interval for hazard ratio; TNM: tumour, node, metastasis. 
age and sex had no independent prognostic value in multivariant analysis.

During the follow-up of $5 \mathrm{yrs}, 530$ of the present series died. Ninety per cent of the patients died of lung cancer. Cardiovascular disease was the most common cause of noncancer deaths (33 patients, $65 \%$ ), which is in agreement with the large cancer patient population study by BRown et al. [13].

\section{Discussion}

Most studies of the prognosis of lung cancer are retrospective and based on cancer registers or selected hospital series, whereas few studies are available on the management or outcome of unselected groups of patients with lung cancer. The present authors collected a prospective series of all new lung cancer patients in a defined geographical area. The patients with a low performance status who had been treated in primary centres without further referral were also included. All the patients were followed-up for 5 yrs or until death. The present study therefore gives information about the survival of lung cancer patients in general. The present authors' previous series of lung cancer patients, some $20 \mathrm{yrs}$ ago [12] was collected using the same prospective method, which thus allows comparison of the survival rates over the years. The results indicate that the overall survival of patients with lung cancer has increased. The 5-yr survival increased during the past 20 yrs from $4 \%$ to $12 \%$, respectively. Since the mean age of the patients increased from $62 \mathrm{yrs}$ to $68 \mathrm{yrs}$, the increase in survival is even more significant.

Only a few similar studies have been reported. A retrospective study from Scotland showed a 2-yr lung cancer patient survival rate of $14 \%$ [6], which is slightly lower than the 2-yr survival in the present study $(19 \%)$. This Scottish study included only patients who had been referred to a specialist for respiratory or thoracic surgical consultation. According to the cancer register, they comprised $63 \%$ of all lung cancer patients in the area and included histological confirmation in $58 \%$ of the cases. A retrospective and register-based study from the Yorkshire region in England showed modest improvement in the prognosis of patients with lung carcinoma as a result of new methods of diagnosis (fibreoptic bronchoscopy) and treatment (chemotherapy for small cell carcinoma) [7]. These patients had been followed-up for $2 \mathrm{yrs}$ and the survival of those with small cell carcinoma increased from 2 to $8 \%$ between 1976 1983.

The histological type of lung cancer has changed over the decades, and the proportion of adenocarcinomas has increased for reasons which are not completely clear $[14,15]$. The present study showed that the 5-yr survival of patients with adenocarcinoma was better $(19 \%)$ than that of patients with other histological types. This is in agreement with the study of WATKIN et al. [8] who used the largest register dataset on lung cancer with $>90 \%$ completeness. This register-based study showed that histological type is an important prognostic factor, and that the patients with adenocarcinoma have the best survival, 5-yr survival being $22 \%$.

The prognosis of small cell carcinoma remains poor. The 5-yr survival of such patients did not change significantly in $20 \mathrm{yrs}$, the 5-yr survival rates being $2 \%$ and $3 \%$. The 2 -yr survival improved from $4 \%$ to $7 \%$. The 5 -yr survival in the present study is similar to that of the register-based study by WATKIN et al. [8] (3.5\%), which also showed improvement in the 2-yr survival of small cell lung cancer from $2.5 \%$ to $7.5 \%$, and improvement in the median survival from 13 to 30 months [8]. Another register-based study showed an increase in the 9-month survival of patients with small cell lung cancer, but no change in the median survival during the years 1976-1983 [7]; the survival of those patients treated with chemotherapy improved significantly. At the time of that study combined multinodality-based chemotherapy had not yet been introduced. Their histological confirmation rate was $58 \%$ and the proportion of small cell carcinomas $10 \%$, the corresponding numbers in the present study being $85 \%$ and $25 \%$, respectively. It should be noted that the purpose of the present study was to evaluate the prevailing treatment of lung cancer in general and its effects on survival and not to compare the survival rates of the patients with different radiation and/or chemotherapy protocols. In conclusion, the long-term survival of patients with small cell lung carcinoma has remained unchanged over the years.

Staging is an important procedure in the application of various treatment modalities [9]. In the present authors earlier series, mediastinal lymph nodes $(\mathrm{N})$ were assessed by mediastinoscopy, whereas CT of the thorax was used in the clinical staging of the present series of patients. Approximately $60 \%$ of the patients underwent CT in this series, a percentage which is remarkably high compared to the corresponding figure $(18 \%)$ in a recent study from Scotland [6]. CT evaluates the whole mediastinum, including the lymph nodes which are not reached by mediastinoscopy, such as the aorta-pulmonary and inferior subcarinal nodes. On the other hand, CT has low specificity and sensitivity in the staging of lung cancer [16]. The relatively good survival of the patients treated surgically in the present series probably reflects better preoperative staging. However, the practice of cardiothoracic surgeons in perioperative staging is often inadequate, which may overestimate the accuracy of preoperative evaluation [17]. A change in stage is more likely when patients are investigated more extensively, with more patients being categorized as having an advanced stage and fewer as having earlier disease. This may be the reason for the relatively low numbers of surgically treated patients in the present series.

Surgery is considered the most effective treatment for nonsmall cell lung cancer $[2,8,18]$. However, only a small proportion of all patients with lung cancer are operated on, $\sim 10 \%$ in Scotland [6], $20 \%$ in the Netherlands [18], 25\% in Spain [19] and 10\% in the USA [20]. Most of these studies have been performed using a hospital series, and hence overestimate the percentage of operated patients. Modern surgical 
techniques allow the resection of fairly large tumours invading neighbouring organs. However, more patients suffer a relapse than are cured by surgery. In the present series, $20 \%$ were operated on and $48 \%$ of the operated patients were alive after 5 yrs, the corresponding numbers in the earlier series being $16 \%$ and $23 \%$, respectively [12]. This result is in line with the study by WATKIN et al. [8] (1974-1986) and BACH et al. [21] (1985-1993) where the outcome of surgically treated patients has continuously improved. Taken together, it is clear that the prognosis of patients with nonsmall cell lung cancer who are operated on has improved over the years.

In the present series, $15 \%$ of the patients had only a clinical diagnosis, and their survival was the worst. It is possible that some of these may not have had lung cancer, despite the clinical diagnosis. There are always patients with poor performance status who do not tolerate invasive investigations. They are often excluded but this causes a bias and gives an unduly optimistic view of the survival of patients with lung cancer.

It appears that screening for lung cancer does not prolong survival $[22,23]$, although the trials are being re-evaluated with a more favourable attitude towards risk-group screening [24]. Recent studies with spiralCT screening also show promising results [25, 26]. Mass radiography surveys of the older population were still performed in Finland during the 1960 1970 s, but this practice had been discontinued before the present survey; consequently the proportion of asymptomatic patients was higher in the earlier $[16 \%]$ than in the present series $(8 \%)$. However, survival was better in the present survey, suggesting that radiographical screening is not effective. Asbestos-induced diseases were screened in some groups of workers in the construction field, shipyards and in the manufacture of asbestos products in Finland during the years 1990-1992 [27]. However, only six out of 602 lung cancer patients in this series were recognized by this screening.

In conclusion, the 5-yr survival of patients with small cell lung cancer has not changed, but the prognosis of patients with nonsmall cell lung cancer is better now when compared to 20 -yrs-ago. In particular, the proportion of surgically treated patients who are alive after 5 yrs has increased.

\section{References}

1. Ries LG, Pollack ES, Young JL. Cancer patient survival: surveillance, epidemiology and end results program, 1973-1979. J Natl Cancer Inst 1983; 70: 693 707.

2. Hirsch FR, Olsen JH, Carstensen B. Lung cancer in Denmark, 1943-1987. In: Hirsch FR, ed. Lung Cancer: Status and Future Perspectives. Copenhagen, Bristol-Myers Squibb, 1993; 10-29.

3. Bonomi P. Review of selected random zed trials in small cell lung cancer. Semin Oncol 1998; 25: 70S-78S.

4. Bunn PA Jr, Yokes EE, Langer CJ, Schiller JH. An update of North American randomized studies in non-small cell lung cancer. Semin Oncol 1998; 25: $2-10 \mathrm{~S}$.

5. Wada H, Tanaka F, Yanagihara K, et al. Time trends and survival after operations for primary lung cancer from 1976 through 1990. J Thorac Cardiovasc Surg 1996; 112: 349-355.

6. Ferguson RJ, Gregor A, Dodds R, Kerr G. Management of lung cancer in South East Scotland. Thorax 1996; 51: 569-574.

7. Connolly CK, Jones WG, Thorogood J, Head C, Muers MF. Investigation, treatment and prognosis of bronchial carcinoma in the Yorkshire Region of England 1976-1983. Br J Cancer 1990; 61: 579-583.

8. Watkin SW, Hayhurst GK, Green JA. Time trends in the outcome of lung cancer management: a study of 9,090 cases diagnosed in the Mersey Region, 1974 1986. Br J Cancer 1990; 61: 590-596.

9. Mountain CF. A new international staging system for lung cancer. Chest 1986; 89: 225S-233S.

10. World Health Organization. Histological Typing of Lung Tumours. International Classification of Tumours. No. 1. 2nd edn. Geneva, World Health Organization, 1981.

11. Feinstein AR, Wells CK. A clinical severity staging system for patients with lung cancer. Medicine 1990; 69: 1-33.

12. Huhti E, Sutinen S, Saloheimo M. Survival among patients with lung cancer. An epidemiologic study. Am Rev Respir Dis 1981; 124: 13-16.

13. Brown BW, Brauner C, Minnotte MC. Noncancer deaths in white adult cancer patients. $J$ Natl Cancer Inst 1993; 85: 979-987.

14. Mäkitaro R, Pääkkö P, Huhti E, Bloigu R, Kinnula VL. An epidemiological study of lung cancer: history and histological types in general population in northern Finland. Eur Respir J 1993; 13: 436-440.

15. Dodds L, Davis S, Polissar L. A population based study of lung cancer incidence trends by histological type, 1974-1981. J Natl Cancer Inst 1986; 76: 21-29.

16. McLoud TC, Bourgouin PM, Greenberg RW, et al. Bronchogenic carcinoma: analysis of staging in the mediastinum with CT by correlative lymph node mapping and sampling. Radiology 1992; 182: 319-323.

17. Tsang GMK, Watson DCT. The practise of cardiothoracic surgeons in the perioperative staging of non-small cell lung cancer. Thorax 1992; 47: 3-5.

18. Damhuis RA, Schutte PR. Resection rates and postoperative mortality in 7899 patients with lung cancer. Eur Respir J 1996; 9: 7-10.

19. Mane JM, Estape J, Sanchez-Loret J, et al. Age and clinical characteristics of 1433 patients with lung cancer. Age Ageing 1994; 23: 28-31.

20. Zagonel V, Pinto A, Sorraino D, et al. Lung cancer in the elderly. Cancer Treat Rev 1994; 20: 315-329.

21. Bach PB, Cramer LD, Warren JL, Begg CB. Racial differences in the treatment of early stage lung cancer. N Engl J Med 1999; 341: 1198-1205.

22. Fontana RS, Sandersson DR, Taylor WF, et al. Early lung cancer detection: results of the initial (prevalence) radiologic and cytologic screening in the Mayo Clinic study. Am Rev Respir Dis 1984; 130: 561-556.

23. Melamed MR, Flehinger BJ, Zaman MB, Hee an RT, Perchick WA, Martini N. Screening for early lung cancer: results of the Memorial Sloan-Kettering study. Chest 1984; 86: 44-53.

24. Strauss GM, Gleason RE, Sugarbaker DJ. Screening 
for lung cancer. Another look; a different view. Chest 1997; 111: 754-768.

25. Sone S, Takashima S, Li F, et al. Mass screening for lung cancer with mobile spiral computed tomography scanner. Lancet 1998; 351: 1242-1245.

26. Henschke CI, McCauley DI, Yankelevitz DF, et al.
Early Lung Cancer Action Project: overall design and findings from baseline screening. Lancet 1999; 354: 99 105.

27. Koskinen K, Rinne JP, Zitting A, et al. Screening for asbestos-induced diseases in Finland. Am J Indust Med 1996; 30: 241-251. 